\title{
Bioacoustic evidence of two uncommon crickets from SW Sardinia, including an analysis of the song of Brachytrupes megacephalus (Lefèvre, 1827) (Orthoptera Gryllidae) in the ultrasonic range
}

Cesare Brizio

World Biodiversity Association, Museo Civico di Storia Naturale di Verona, Lungadige Porta Vittoria 9, 37129 Verona, Italy; email: briziocesare@gmail.com

\begin{abstract}
Two elusive species of crickets, Natula averni (A. Costa, 1855) (Orthoptera Gryllidae Trigonidiinae), and Brachytrupes megacephalus (Lefèvre, 1827) (Orthoptera Gryllidae Gryllinae) are reported from SW Sardinia based on recordings with $96 \mathrm{kHz}$ sample frequency. The song of the latter species, that was observed and photographed during song emission, is also recorded at a sample frequency of $250 \mathrm{kHz}$, revealing harmonic components up to $100 \mathrm{kHz}$ and above.
\end{abstract}

KEY WORDS Orthoptera; Brachytrupes; Natula; Sardinia; Biogeography; Bioacoustics.

Received 23.04.2018; accepted 13.05.2018; printed 30.06.2018; published online 05.07.2018

\section{INTRODUCTION}

Previous bioacoustics studies by the author in the same geographic area (Brizio \& Buzzetti, 2014; Brizio, 2015) have demonstrated the effectiveness on the field of low cost USB microphones capable of recording ultrasounds thanks to high sampling frequency $(250 \mathrm{kHz})$, the consistency of such recordings with those obtained with a $96 \mathrm{kHz}$ audible band digital recorder, and the possibility to identify different species on the basis of their song, as well as to derive novel information from an analysis of high frequency components of the songs, previously unreported in the scientific literature: an observation limited to audible frequencies, or to the 0-48 $\mathrm{kHz}$ range provided by $96 \mathrm{kHz}$ recordings, may deliver incomplete or misleading results.

In this short paper, the same techniques cited above are applied to the bioacoustic identification and to the analysis of the song of two elusive species of Orthoptera Gryllidae: Natula averni (A. Costa, 1855), also described as "the most mysterious orthopteran of Europe" (Odé et al., 2011), and the biggest European cricket, Brachytrupes megacephalus (Lefèvre, 1827), capable to emit an exceptionally powerful song. Although lacking field equipment to measure absolute acoustic pressure, based on the direct experience of close contact with both species, the author subjectively feels that the volume of the song of $B$. megacephalus matches or exceeds the volume of the songs by Gryllotalpa vineae Bennet-Clark, 1970, the latter species reportedly reaching $80 \mathrm{~dB}$ at 2 meters above the burrow (Bennet-Clark, 1970a, b).

In the following pages, the analysis of the song of $B$. megacephalus will reveal a previously unreported, exceptionally rich harmonic structure, extending well into the ultrasonic domain. 


\section{MATERIAL AND METHODS}

To ensure consistency with previous analyses (Brizio \& Buzzetti, 2014; Brizio, 2015), the same methods have been applied here.

All the species reported were recorded within a $10 \mathrm{~km}$ range from Fluminimaggiore (CarboniaIglesias Province, Sardinia, Italy) (Figs. 1-5).

All the audio material was obtained by field recording. Specimens were not captured nor recorded in constrained conditions.

Recording equipment included a Zoom H1 handheld digital Micro-SD recorder, coupled with a self-built stick stereo microphone using Panasonic WM-64 capsules from an Edirol R-09 digital recorder.

Acoustic recordings were taken in stereo, 16 bit, with a $96 \mathrm{kHz}$ sampling frequency, and thus covering frequencies up to $48 \mathrm{kHz}$. The audio samples where obtained in the field, in windy conditions. Having observed no meaningful pattern in the lowest frequency range, to improve the clarity of the successive analyses and illustrations, an 18th order Chebychev Type 1 high pass filter was applied, with cut-off frequency at $150 \mathrm{~Hz}$.

Due to atmospheric conditions, the left channel of the stereo microphone recorded a significant amount of noise. To the purpose of the analyses per- formed, the audio from the right channel was doubled in the left channel with no variation, before merging the two channels in one monophonic recording.

Ultrasound monophonic recording at a $250 \mathrm{kHz}$ sampling frequency was performed via a Dodotronic Ultramic 250 microphone connected via USB cable to an Asus Eee PC 1225B notebook personal computer, using SeaWave software by CIBRA-University of Pavia's "Centro Interdisciplinare di Bioacustica e Ricerche Ambientali". Originally received as amplitude data $(\mathrm{mV})$ by the recording apparatus, software normalized spectral energy is expressed in decibels. Sound pressure is expressed in dB Full Scale.

Oscillograms, spectrograms, and frequency analysis diagrams were generated by Adobe Audition 1.0 software. To give more evidence even to the faintest significant spectral components, or to improve readability of frequency/volume analyses, screenshots were contrast-enhanced with Adobe Photoshop Elements 4.0 by a procedure involving in sequence: color removal, image inversion, brightness and contrast adjustment, shadows/highlights adjustment. Those interventions did not affect the accuracy of rendering.

The illustrations of frequency analyses where generated with a scan of the entire audio sample

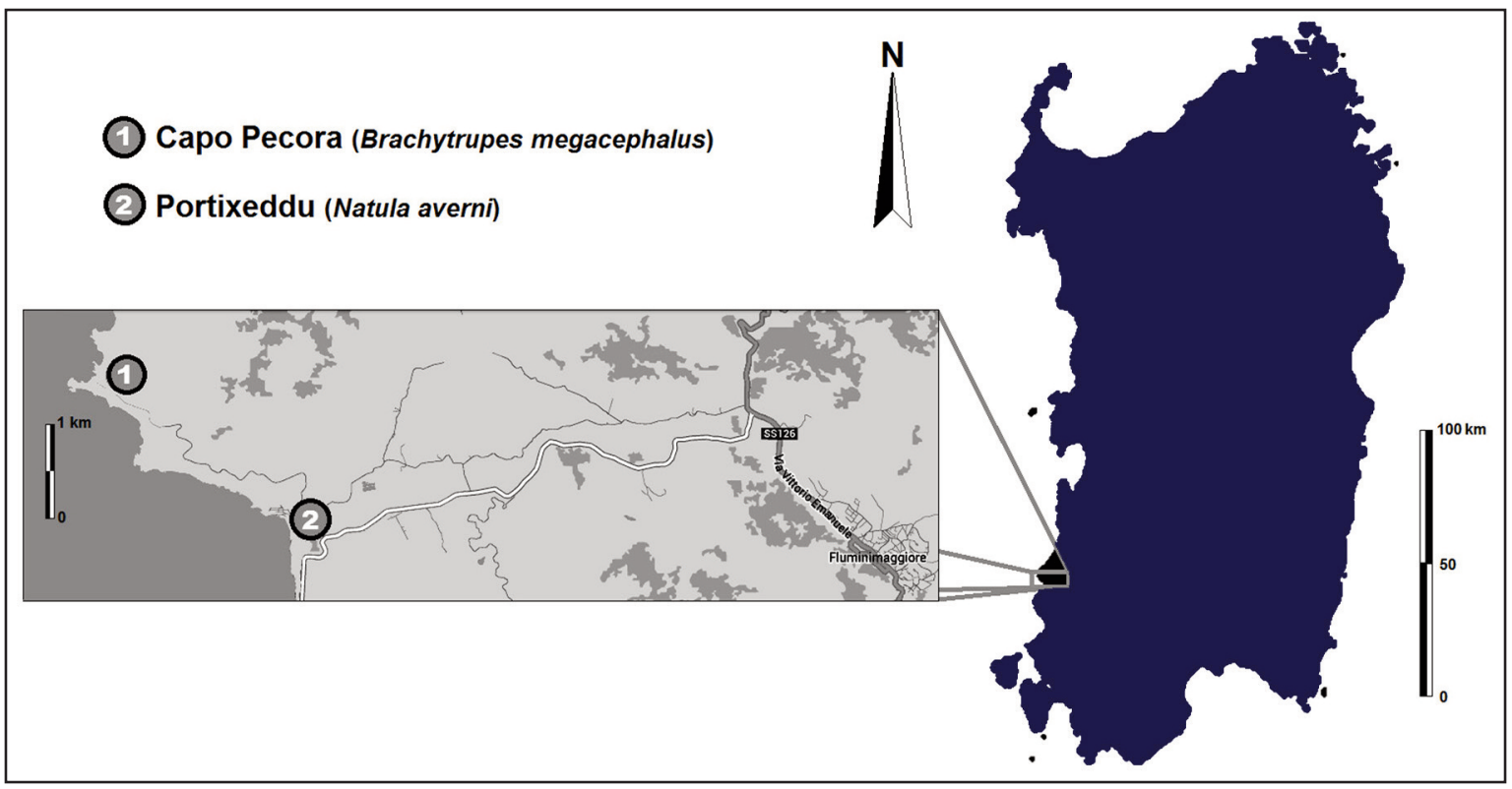

Figure 1. Map of the recording stations of Capo Pecora and Portixeddu, Sardinia. 
(Table 1, column "Interval analysed") and with an FFT size of 4096 byte, capable to render a smoother and clearer picture. All the software cited operates under Windows 7 64-bit operating system.

Brizio \& Buzzetti, 2014, address in more detail some technical requirements of Ultramic 250 and proposed a specific operating protocol to ensure comparability between Ultramic recordings and audio range recordings available in literature. Brizio (2015) describes in more detail the challenges of ultrasound field recording and the requirement to obtain a recording as near as possible to the singing animal, to avoid the attenuation of faint high-order harmonic components.

\section{RESULTS}

\section{Systematics}

Ordo ORTHOPTERA Burmeister, 1839

Familia GRYLLIDAE Laicharting, 1871

Subfamilia TRIGONIDIINAE Saussure, 1874

Genus Natula Gorochov, 1987

Natula averni (A. Costa, 1855)

EVIDENCE COLLECTED. Bioacoustical.

EXAMINED MATERIAL. Four $96 \mathrm{kHz}$ recordings (Table 1) from Italy, Sardinia, Portixeddu (Carbonia-Iglesias Province), 24.IV.2018, 39²6’21.20”N N - 8०24'46.84'”, 0 meter asl.

Distribution. General distribution in Italy of this species, as reported by Odé et al. (2011) includes Campania (Averno: Costa, 1855; TargioniTozzetti, 1878). Schmidt \& Hermann (2000) reported for Sardinia Anaxipha longipennis (Audinet-Serville, 1839), a species that, according to Odé et al. (2011), may be a synonym of $N$. averni. Boittier et al. $(2006,2007)$ reported $N$. averni from Corsica. For other data, see Massa et al. (2012).

REMARKS. Although unaided by visual recognition, due to the elusiveness of this very small species and to its habitat (reed vegetation along rivers near the sea, as confirmed by Odé et al., 2011), posing unsurmountable problems in the localization of this $1 \mathrm{~cm}$ long insect, identification poses no doubt, both for its habitat (Fig. 2) and for the unequivocal identification of the pattern and of

\begin{tabular}{|c|c|c|c|}
\hline Audio samples examined & \begin{tabular}{|l|} 
Duration \\
(mm:ss)
\end{tabular} & $\begin{array}{c}\text { Sampling } \\
\text { frequency }\end{array}$ & $\begin{array}{c}\text { Interval Analyzed i } \\
\text { figures } 6.16\end{array}$ \\
\hline B_megacephalus_CPecora_20180422-205622.wav & $00: 37$ & $250 \mathrm{kHz}$ & \\
\hline B_megacephalus_C_Pecora_20180422-205757.wav & 18 & $0 \mathrm{kHz}$ & \multirow{3}{*}{ not illustrated } \\
\hline B_megacephalus_C_Pecora_20180422-205423.wav & $00: 53$ & $250 \mathrm{kHz}$ & \\
\hline B_megacephalus_C_Pecora_20180422-205208.wav & $00: 34$ & $250 \mathrm{kHz}$ & \\
\hline B_megacephalus_CapoPecora_21_04_2018_A.WAV & $00: 35$ & $96 \mathrm{kHz}$ & $0: 21: 00$ to 0:26:00 \\
\hline B_megacephalus_CapoPec & $00: 21$ & $96 \mathrm{kHz}$ & not illustrated \\
\hline Natula averni Portixeddu 24_04_2018 18_30 A.WAV & $01: 35$ & $96 \mathrm{kHz}$ & $0: 42: 00$ to 1:00:0 \\
\hline Natula averni Portixeddu 24_04_2018 18_30 B.WWV & $03: 19$ & $96 \mathrm{kHz}$ & \multirow{3}{*}{ not illustrated } \\
\hline Natula averni Portixeddu 24 O04_2018 18 30 C.WAV & $02: 02$ & $96 \mathrm{kHz}$ & \\
\hline Natula averni Portixeddu 24_04_2018 18_30 D.WWV & 00:40 & $96 \mathrm{kHz}$ & \\
\hline
\end{tabular}

Table 1. List of the audio samples examined in this paper. Also the recording whose analysis is not illustrated, were found consistent with the audio samples deetailed in this paper.

\begin{tabular}{|c|c|c|c|c|}
\hline Peak number & $\begin{array}{c}\text { Acoustic } \\
\text { pressure } \\
\mathrm{dBfs}\end{array}$ & $\begin{array}{c}\text { Peak } \\
\text { frequency } \\
\mathrm{Hz}\end{array}$ & $\begin{array}{c}\text { Theoretical } \\
\text { Harmonic } \\
\text { Frequency } \mathrm{Hz}\end{array}$ & $\begin{array}{c}\text { \% difference } \\
\text { with the Nth } \\
\text { Harmonic }\end{array}$ \\
\hline Fundamental & -25.03 & 6469 & -- & -- \\
\hline Secondary Peak & -57.95 & 12350 & -- & -- \\
\hline 2nd Harmonic & -55.43 & 12980 & 12938 & $0.32 \%$ \\
\hline Secondary Peak & -69.86 & 19170 & -- & -- \\
\hline 3rd Harmonic & -67.69 & 19450 & 19407 & $0.22 \%$ \\
\hline 4rd Harmonic & .70 .6 & 25940 & 25876 & $0.25 \%$ \\
\hline
\end{tabular}

Table 2. Numeric data from the frequency analysis of a 96 $\mathrm{kHz}$ recording of Natula averni, Portixeddu, 24.IV.2018.

\begin{tabular}{|c|c|c|c|c|c|c|c|c|c|}
\hline \multirow{2}{*}{$\begin{array}{l}\text { Sample frequency } \\
\text { Peak number }\end{array}$} & \multicolumn{4}{|c|}{$96 \mathrm{kHz}$} & \multicolumn{5}{|c|}{$250 \mathrm{kHz}$} \\
\hline & \begin{tabular}{|c|}
$\begin{array}{c}\text { Acoustic } \\
\text { pressure } \\
\text { dBfs }\end{array}$ \\
\end{tabular} & \begin{tabular}{|c|} 
Peak \\
frequency \\
$\mathrm{Hz}$
\end{tabular} & \begin{tabular}{|l|} 
Theoretical \\
Harmonic \\
Freq. (Hz) \\
\end{tabular} & \begin{tabular}{|c|} 
\% difference \\
with the Nth \\
Harmonic
\end{tabular} & \begin{tabular}{|c|} 
Acoustic \\
pressure \\
dBfs \\
\end{tabular} & \begin{tabular}{|c|} 
Peak \\
frequency \\
$\mathrm{Hz}$ \\
\end{tabular} & \begin{tabular}{|l|} 
Theoretical \\
Harmonic \\
Freq. $(\mathrm{Hz})$ \\
\end{tabular} & \begin{tabular}{|c|}
$\begin{array}{c}\text { \%difference } \\
\text { with the Nth } \\
\text { Harmonic }\end{array}$ \\
\end{tabular} & \begin{tabular}{|l|}
$\%$ difference \\
with $5800 \mathrm{~Hz}$ \\
Harmonics
\end{tabular} \\
\hline Fundamental & \begin{tabular}{|l|l|}
.19 .58 \\
\end{tabular} & 5812 & \begin{tabular}{|l|}
.- \\
\end{tabular} & 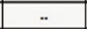 & \begin{tabular}{|l|}
15.02 \\
\end{tabular} & 5920 & . & .. & .. \\
\hline 2nd Harmonic & .27 .78 & 11740 & 11624 & $0.99 \%$ & .19 .65 & 11770 & 11840 & $0.59 \%$ & $1.44 \%$ \\
\hline Secondary peak & .60 & -16300 & 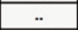 & & 3.17 & 16350 &.. &.. &.. \\
\hline 3rd Harmonic & .54 .64 & 17710 & 17436 & $1.55 \%$ & .43 .92 & 17510 & 17760 & $1.43 \%$ & $0.63 \%$ \\
\hline Secondary peak &.. &. & 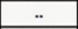 & 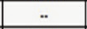 & $.40,59$ & 23070 & 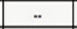 & 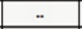 & 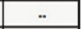 \\
\hline 4th Harmonic & $.64,85$ & 23250 & 23248 & $0.01 \%$ & .40 .42 & 24290 & 23680 & $2.51 \%$ & $4.49 \%$ \\
\hline Secondary peak & & & & & .58 .76 & 27640 & & & \\
\hline 5th Harmonic & .70 .04 & 29360 & 29060 & $1.02 \%$ & .56 .17 & 29050 & 29600 & $1.89 \%$ & $0.17 \%$ \\
\hline 6th Harmonic & .76 .11 & 35410 & 34872 & $1.52 \%$ & .61 .57 & 34850 & 35520 & $1.92 \%$ & $0.14 \%$ \\
\hline 7th Harmonic & $.79,73$ & 41100 & 40684 & $1.01 \%$ & .63 .55 & 41070 & 41440 & $0.90 \%$ & $1.14 \%$ \\
\hline Secondary peak & .85 & -42700 & $\pi$ & & .64 .81 & 42780 &.$\cdot$ &.. & 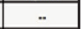 \\
\hline Secondary peak & 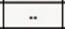 & 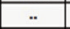 & .* & 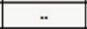 & .68 .04 & 44730 & 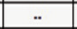 & 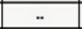 &. \\
\hline 8th Harmonic & .82 .92 & 46920 & 46496 & $0.90 \%$ & .63 .04 & 46560 & 47360 & $1.72 \%$ & $0.34 \%$ \\
\hline 9th Harmonic & 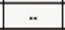 & 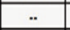 &.. & 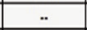 & .64 .52 & 52360 & 53280 & $1.76 \%$ & $0.31 \%$ \\
\hline 10th Harmonic & 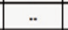 & - & .. & 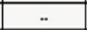 & .67 .53 & 58220 & 59200 & & $0.38 \%$ \\
\hline 11th Harmonic & $\ddot{*}$ & - &. & 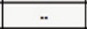 & .69 .28 & 64080 & 65120 & $1.62 \%$ & $0.44 \%$ \\
\hline 12th Harmonic &. &. &. &. & $.71,6$ & 69760 & 71040 & $1.83 \%$ & $0.23 \%$ \\
\hline 1 13th Harmonic & 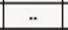 & - & $\ddot{.}$ & $\ddot{-}$ & .74 .24 & 75500 & 76960 & $1.93 \%$ & $0.13 \%$ \\
\hline 14th Harmonic &. & 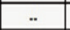 &. & 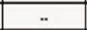 & .76 & 81350 & 82880 & $1.88 \%$ & $0.18 \%$ \\
\hline 15 th Harmonic &. & . & & 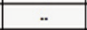 & .77 .43 & 87210 & 88800 & $1.82 \%$ & $0.24 \%$ \\
\hline 16th Harmonic &. & 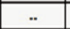 &. &. & .79 .63 & 93200 & 94720 & $1.63 \%$ & $0.43 \%$ \\
\hline 17th Harmonic & 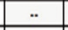 &. &. & 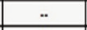 & .80 .08 & 98870 & 100640 & $1.79 \%$ & $0.27 \%$ \\
\hline 18th Harmonic & 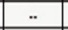 & - & 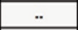 & 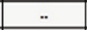 & .80 .02 & 104670 & 106550 & $1.81 \%$ & $0.26 \%$ \\
\hline 19th Harmonic & 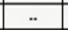 &. &. & 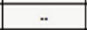 & .80 .41 & 110650 & 112480 & $1.65 \%$ & $0.41 \%$ \\
\hline & $\ddot{*}$ & 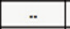 & $\ddot{*}$ & 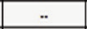 & .79 .93 & 116390 & 118400 & $1.73 \%$ & $0.34 \%$ \\
\hline 21th Harmonic & .. & -. &. & 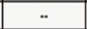 & .77 .09 & 121700 & 124320 & $2,15 \%$ & $0.08 \%$ \\
\hline
\end{tabular}

Table 3. Numeric data from the frequency analysis of 96 $\mathrm{kHz}$ and $250 \mathrm{kHz}$ recordings of Brachytrupes megacephalus, Capo Pecora, 21-22.IV.2018. Only the most relevant among the secondary peaks are considered in this table. 
the harmonic structure well noted for the species and reported by Odé et al. (2011).

Figures 6-8 are self-explanatory and describe clearly the pattern and the structure of the song of $N$. averni, recorded at an air temperature around $22^{\circ} \mathrm{C}$. The song observed consisted of echemes lasting around $250 \mathrm{~ms}$, regularly repeated at the rate of about 2/s. Echemes consist of about 10-20 syllables with a slight volume increase in the first four syllables, then equally loud. Frequency analysis in figure 8 and Table 2 shows the main volume peak at the fundamental frequency of around $6500 \mathrm{~Hz}$, with three well-defined harmonics, the 2 nd and the 3 rd of which are preceded by a clearly discernible secondary peak.

The particular nature of the habitat, that made very difficult the handling of a portable computer, as well as the complete absence of any hint of highorder harmonic components in the $96 \mathrm{kHz}$ recording, discouraged the attempt to record this species at a $250 \mathrm{kHz}$ sampling frequency.

Subfamilia GRYLLINAE Laicharting, 1871 Genus Brachytrupes Serville, 1839

Brachytrupes megacephalus (Lefèvre, 1827)

EVIDENCE COLLECTED. Bioacoustical and photographic.

EXAMINED MATERIAL. Two $96 \mathrm{kHz}$ and four 250 $\mathrm{kHz}$ recordings (Table 1) from Italy, Sardinia, Capo
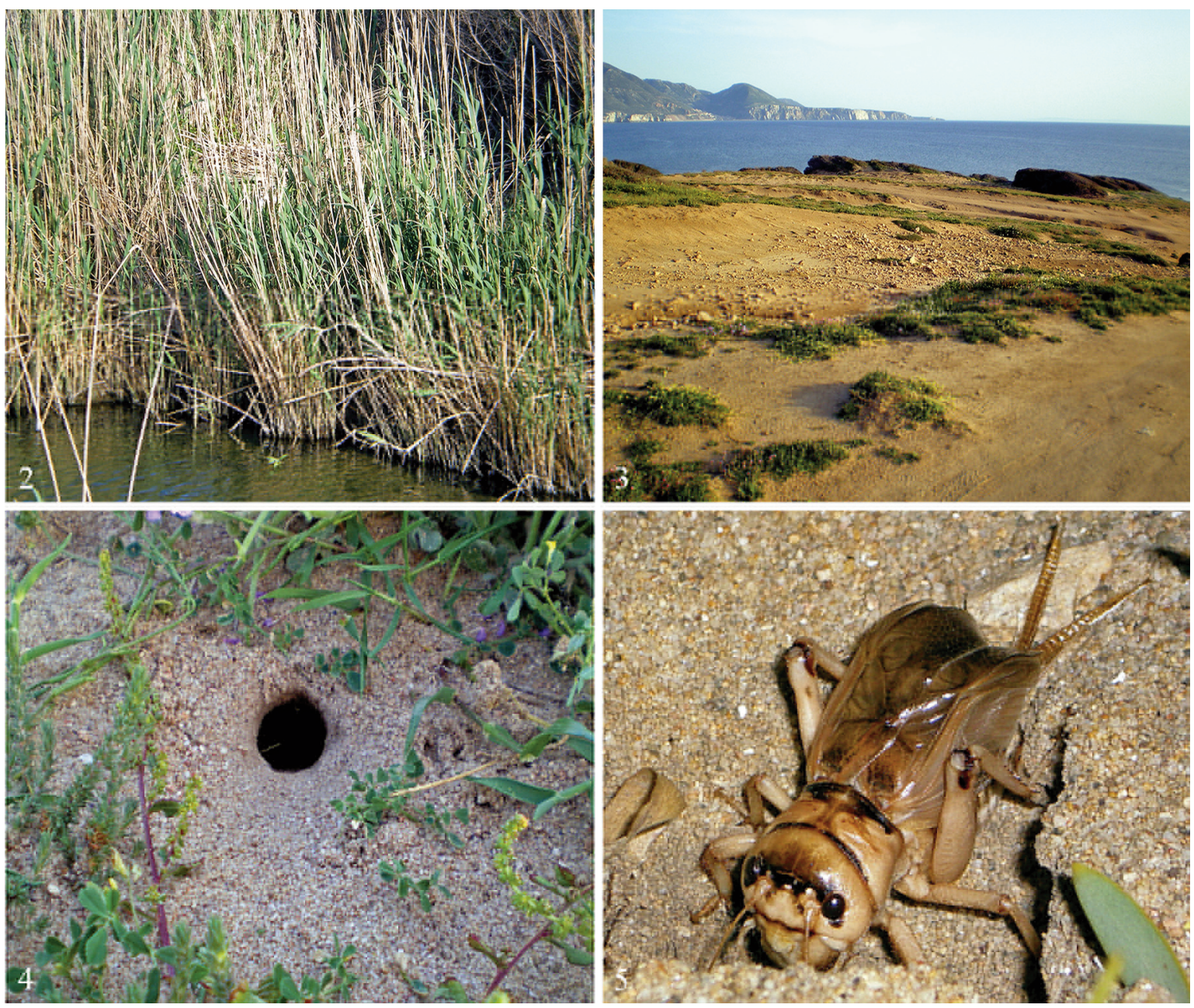

Figure 2. The recording station of Natula averni, Portixeddu, 24.IV.2018. Figure 3. The recording station of Brachytrupes megacephalus, Capo Pecora, 21-22.IV.2018. Figure 4. A typical burrow of B. megacephalus, Capo Pecora, 21-22.IV.2018. Figure 5. Habitus of B.megacephalus, Capo Pecora, 22.IV.2018. 
Pecora (Medio Campidano Province), 2122.IV.2018, 39²7’3.27’N - 8²3'46.67'E, 20 meters asl. Air temperature around $19^{\circ} \mathrm{C} / 20^{\circ} \mathrm{C}$.

DisTRIBUTION. It's the only Italian representative of the genus. General distribution in Italy of this species, as reported by Odé et al. (2011) includes Sicily as type locality, and Southern Sardinia (Zanardi, 1964; Baccetti, 1991; Schmidt \& Hermann, 2000; Galvagni, 2010). However, the species is widespread in North Africa and is reported also from the Maltese islands. For other data see Massa et al. (2012).

REMARKS. Both the song and the habitus of this species are unmistakeable. Songs were recorded and specimens were observed on the promontory of Capo Pecora, delimited by granitic cliffs and boulders. In the plateau topping the promontory, the species burrows in the coarse sand resulting from the weathering of granite.

The burrows, the habitus, and the behaviour of the specimen, observed and photographed while singing, corresponded with the description by Odé et al. (2011).

The impressive looks of this cricket have no equal in the Italian fauna. The specimens, that sing during the spring, especially in April, emerge from their burrows at twilight and are very suspicious, ready to re-enter their den if disturbed. Even though the song can be heard from great distance and easily traced, to get the best recording and photographic opportunities, it is better to search for the dens and mark their position for successive visits, considering that the source of such a powerful song, subjectively perceived as reaching $80 \mathrm{~dB}$ at around $2 \mathrm{~m}$ above and behind the animal, is uneasy to locate precisely.

Provided that any noise and rapid movements are avoided, the specimens can be illuminated and observed, in particular during the emission of the song, whose almost unbelievably high volume, with the physical excerption required, apparently saturates the perceptive faculties of the cricket, to the point when it can be lightly touched without escaping.

The pattern described by Odé et al. (2011) was observed: syllables continuously repeated at a rate of around 130/sec.

The recordings at $96 \mathrm{kHz}$ and $250 \mathrm{kHz}$ yielded consistent results, reported in Table 3 .

In both the types of recording, the first seven "octaves", delimited by the fundamental frequency

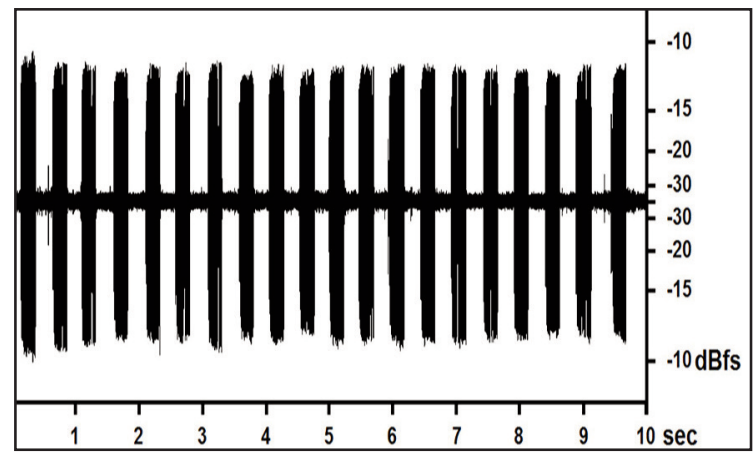

Figure 6. Oscillogram of a $96 \mathrm{kHz}$ audio sample of Natula averni, Portixeddu, 24.IV.2018.

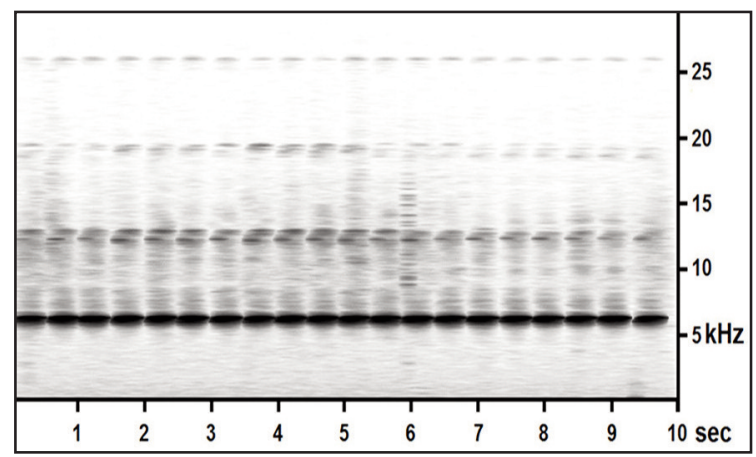

Figure 7. Time/frequency spectrogram of a $96 \mathrm{kHz}$ audio sample of Natula averni, Portixeddu, 24.IV.2018.

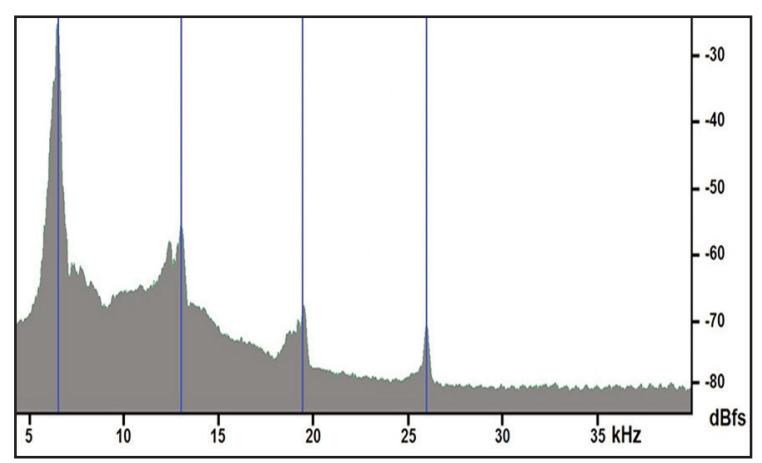

Figure 8. Frequency/volume analysis of a $96 \mathrm{kHz}$ audio sample of Natula averni, Portixeddu, 24.IV.2018. Blue lines mark the fundamental frequency and its harmonics.

and the first seven harmonics, can be clearly made out in both the analyses (Figures 13,14) and in both the time/frequency spectrograms (Figures 10, 12). Furthermore, as can be expected from an highly stressed sounding apparatus, secondary peaks and clusters of ancillary frequencies are generated. 


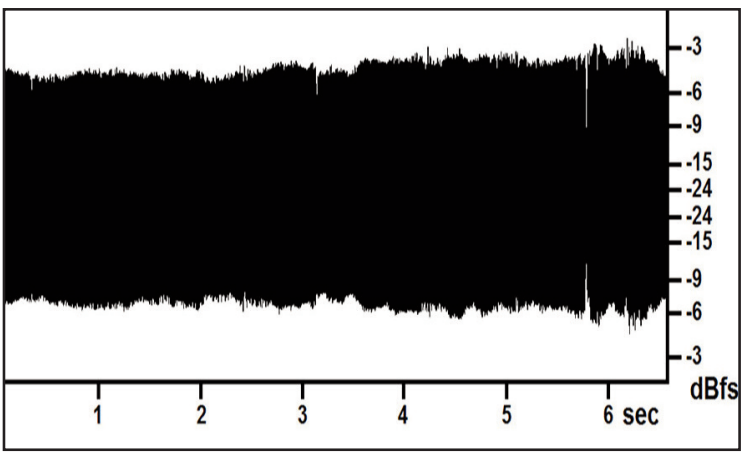

Figure 9. Oscillogram of a $96 \mathrm{kHz}$ audio sample of Brachytrupes megacephalus, Capo Pecora, 21.IV.2018.

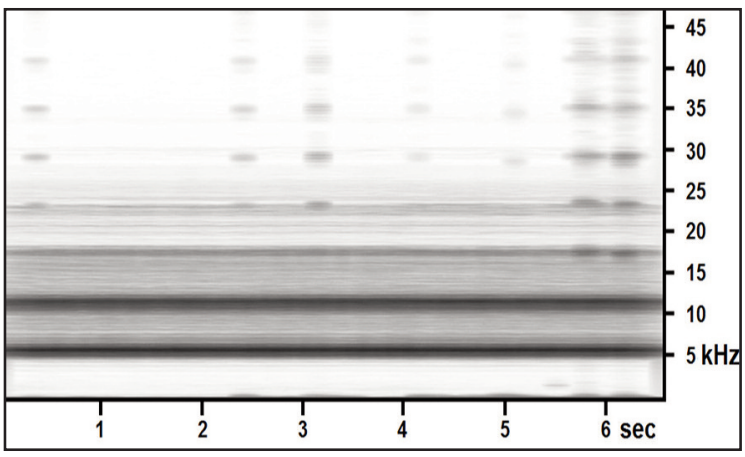

Figure 10. Time/frequency spectrogram of a $96 \mathrm{kHz}$ audio sample of Brachytrupes megacephalus, Capo Pecora, 21.IV.2018.

All the main elements are reported in Table 3.

A strong harmonic structure is observed in the frequency/volume analysis of the wide band, 250 $\mathrm{kHz}$ sampling frequency recording, with a geometrical progression of octaves delimited by peaks corresponding with the fundamental frequency and its first twenty-one harmonics in geometrically decreasing intensity. All the high order (above $50 \mathrm{kHz}$ ) harmonics are in better accordance with a $5800 \mathrm{~Hz}$ fundamental, the same observed in the $96 \mathrm{kHz}$ recordings. An accessory cusp can be observed in the $15-50 \mathrm{kHz}$ range, around $1500 \mathrm{kHz}$ below each harmonic frequency, with comparable intensity. A more complex cluster of secondary peaks, among which a two-cusps, regularly repeated pattern, is evident at middle octave in the $5-58 \mathrm{kHz}$ range. Despite the technical differences in microphone sensitivity and recording device, the analysis of the $96 \mathrm{kHz}$ recording reproduces quite faithfully in the $0-48 \mathrm{kHz}$ range the complex pattern described above.

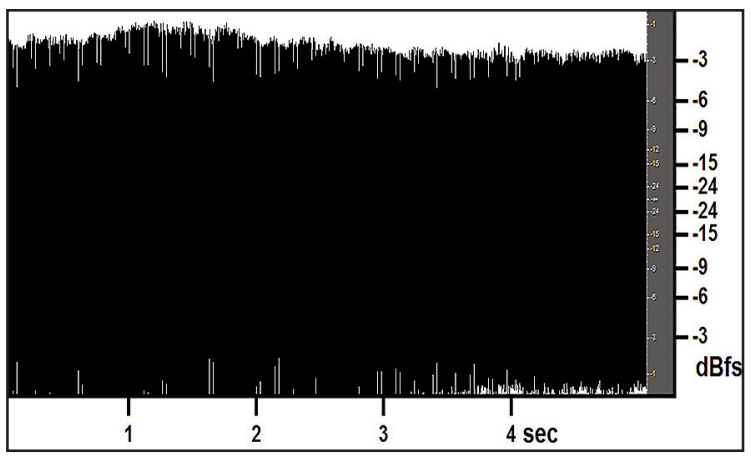

Figure 11. Oscillogram of a $250 \mathrm{kHz}$ audio sample of Brachytrupes megacephalus, Capo Pecora, 22.IV.2018.

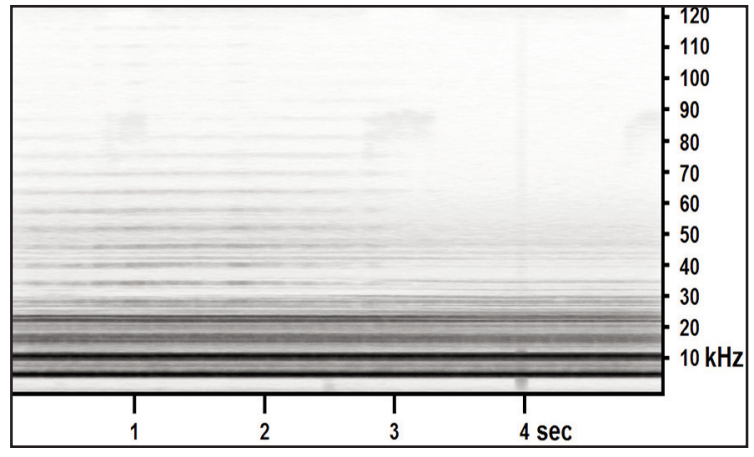

Figure 12. Time/frequency spectrogram of a $250 \mathrm{kHz}$ audio sample of Brachytrupes megacephalus, Capo Pecora, 22.IV.2018.

\section{CONCLUSIONS}

The songs of two uncommon crickets from Sardinia have been digitally recorded in the field, one of them by a low-cost USB microphone capable of generating 0 to $125 \mathrm{kHz}$ monophonic recordings, including both audible and inaudible frequencies. This device, Ultramic 250, by generating results consistent with other recording methods and by providing useful information about high-frequency components above $20 \mathrm{kHz}$ and up to $125 \mathrm{kHz}$, allowed to observe a previously unreported high-order harmonic structure for the song of the biggest European cricket, B. megacephalus. In addition, the underreported and very elusive, $N$. averni, whose systematic status may need some revision (Odé et al., 2011), was recorded and analysed in the $0-48 \mathrm{kHz}$ range, revealing a well-defined progression of harmonics above its maximum volume frequency. 


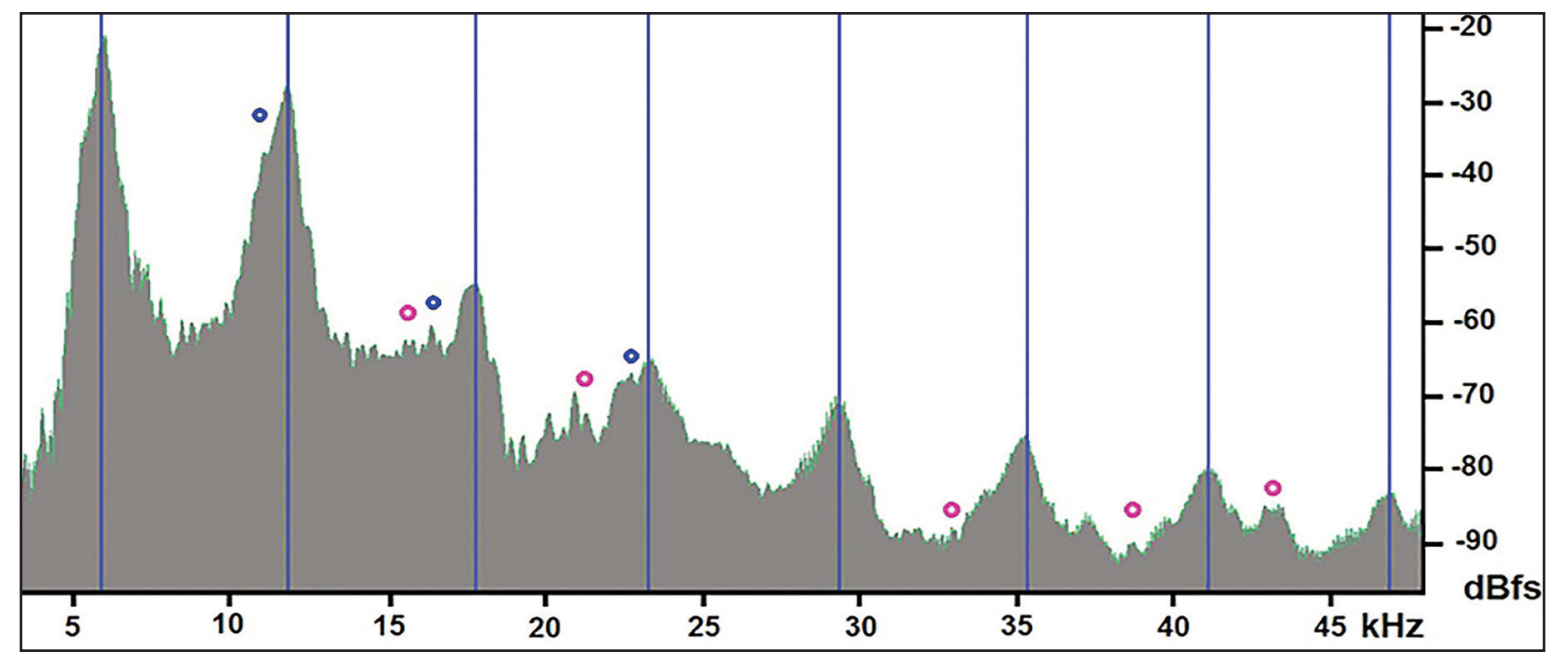

Figure 13. Frequency/volume analysis of a $96 \mathrm{kHz}$ audio sample of Brachytrupes megacephalus, Capo Pecora, 21.IV.2018. Blue lines mark the fundamental frequency and its harmonics. Blue circles mark the secondary peaks preceding some harmonics. Magenta circles mark frequency clusters also observed in the $250 \mathrm{kHz}$ recordings.

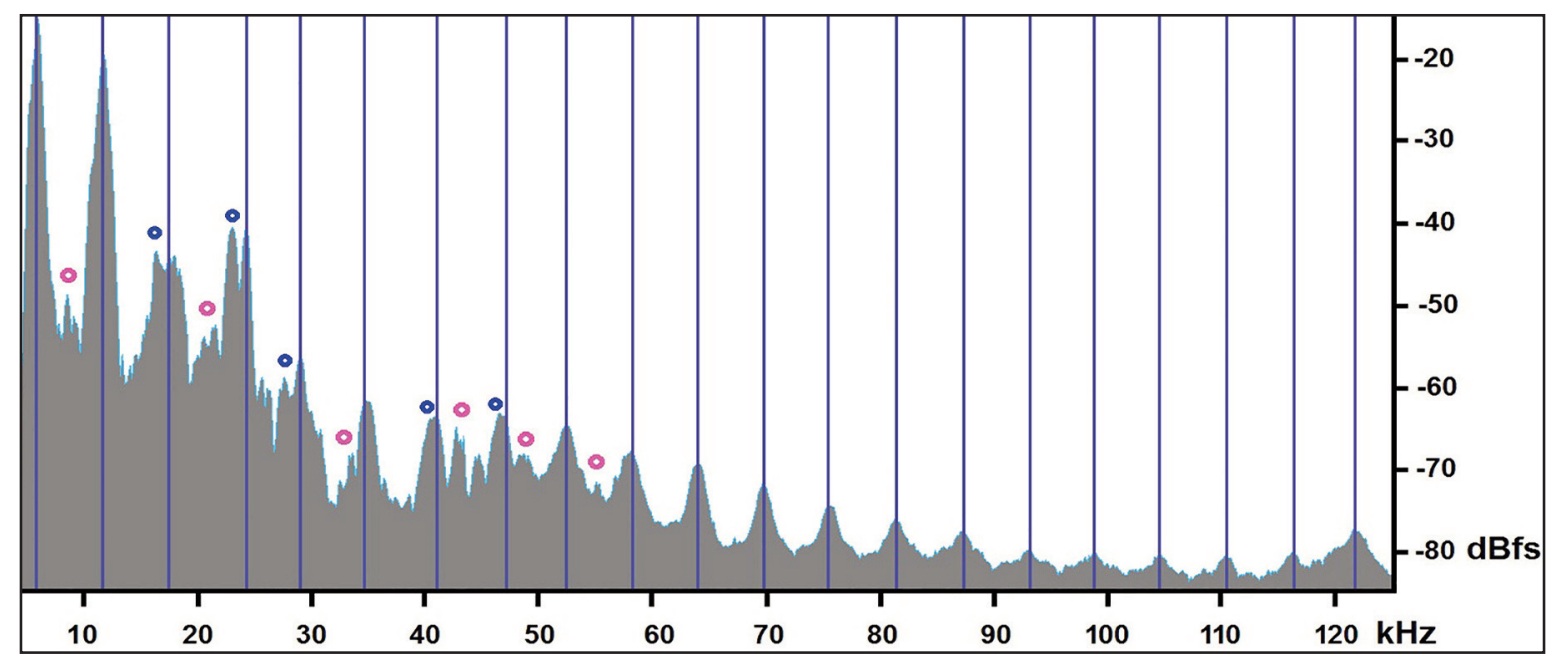

Figure 14. Frequency/volume analysis of a $250 \mathrm{kHz}$ audio sample of Brachytrupes megacephalus, Capo Pecora, 22.IV.2018. Blue lines mark the fundamental frequency and its harmonics. Blue circles mark the secondary peaks preceding some harmonics. Magenta circles mark regularly repeated frequency clusters, some of which also observed in the $96 \mathrm{kHz}$ recordings.

Considering the restricted habitat of both the species examined, the value of this report may be regarded both as ecological and biogeographical, as well as bioacoustic.

\section{REFERENCES}

Baccetti B., 1991. Notulae Orthopterologicae. 51. Osservazioni corologiche su alcuni Ortotteri del centro Italia. Redia, 74: 525-532.
Bennet-Clark H.C., 1970a. A new French mole cricket, differing in song and morphology from Gryllotalpa gryllotalpa L. (Orthoptera: Gryllotalpidae). Proceedings of the Royal Entomological Society of London (B), 39: 125-132.

Bennet-Clark H.C., 1970b. The mechanism and efficiency of sound production in mole crickets. Journal of Experimental Biology, 53: 619-652.

Boitier E., Petit D. \& Bardet O., 2006. Contribution à la connaissance des Orthoptéroïdes de Corse (Orthoptera Phasmoptera Mantodea). Entomologiste, 62: 129-145. 
Boitier E., Petit D. \& Bardet O., 2007. Deuxième voyage naturaliste en Corse: contribution à la connaissance des Orthoptères (juillet-août 2006). Rapport d'étape Office de l'Environnement de la Corse et Alcided'Orbigny, Clermont-Ferrand (mars 2007), 13 pp. et annexes.

Brizio C., 2015. High frequency components of the songs of two Cicadas (Hemiptera Cicadidae) from Sardinia (Italy) investigated by a low-cost USB microphone. Biodiversity Journal, 6: 41-52.

Brizio C. \& Buzzetti F.M., 2014. Ultrasound recordings of some Orthoptera from Sardinia (Italy). Biodiversity Journal, 5: 25-38.

Costa A., 1855. Seguito a Grillidei. In: Costa O.G. (Ed.), Fauna del Regno di Napoli. Napoli: 29-52.

Galvagni A., 2010. Ricerche sulla fauna degli Ortotteroidei nella Sardegna sud-occidentale (Blattaria, Mantodea, Orthoptera, Phasmatodea). Atti della Accademia roveretana degli Agiati, 260 XB: 133 196.
Massa B., Fontana P., Buzzetti F. M., Kleukers R. \& Odé B., 2012. Fauna d'Italia, vol. XLVIII, Orthoptera. Calderini, 563 pag. + DVD.

Odé B., Kleukers R., Forbicioni L., Massa B., Roesti C., Boitier E. \& Braud Y., 2011. In search of the most mysterious orthopteran of Europe: the Reed cricket Natula averni (Orthoptera: Gryllidae). Articulata, 26: 51-65.

Schmidt G.H. \& Herrmann M., 2000. Occurrence and distribution of Orthopteroidea, Blattoptera, Mantodea, Phasmodea and Dermaptera in Sardinia/Italy. Bollettino della Società Sarda di Scienze Naturali, 32: 83-128.

Targioni Tozzetti A., 1878. Prospetto dei generi e delle specie di Ortotteri proprii all'Italia. Annali di Agricoltura, Ministero dell'Interno, 1: 36-135.

Zanardi D., 1964. Un singolare insetto dannoso a vigneti e orti in Sardegna. Il Brachytrupes megacephalus Lefeb. Il Coltivatore e Il Giornale Vinicolo Italiano, 110: 370-375. 